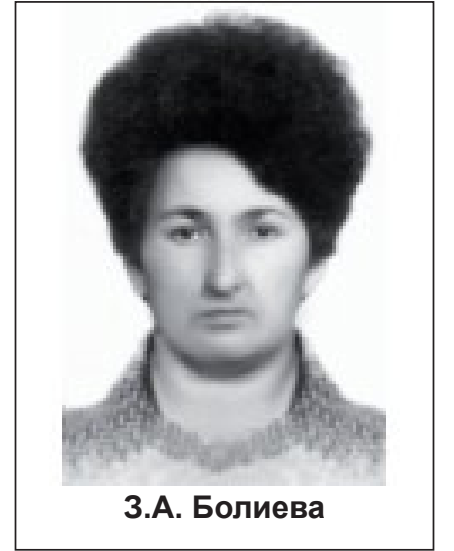

\section{ВВЕДЕНИЕ}

Оценивая стратегию интенсификации растениеводства в XXI столетии, необходимо учитывать исчерпаемость жизнеобеспечивающих ресурсов Земли, опасность техногенной нагрузки на биосферу. Ввиду этого в последнее время большое внимание уделяется экологической обстановке, в которой оказались живые организмы, в том числе и растительный мир. Вследствие этого внимание ученых к техногенным фракторам во внешней среде обосновано, так как через сравнительно короткое время остро встанет вопрос о сохранении всего живого на нашей планете. Поэтому в связи с глобальными проблемами экологии важное значение приобретает поиск природных, низкозатратных ресурсов, стимулирующих рост и развитие растений, снижение их заболеваемости $[3,4,6,7,8]$.

Успехи, достигнутые за последние годы в изучении ффизики низких температур, в значительной мере способствовали широкому использованию холода в биологии и медицине. В результате возникла новая наука - криобиология. Криобиологические исследования в нашей стране и за рубежом свидетельствуют об актуальности данной программы для решения ряда важнейших народнохозяйственных проблем [12].

Следует отметить, что большой вклад в развитие науки криобиологии внесли многие ученые $[13,14]$.

Исследованиями доказано, что действие низких температур изучается на разных уровнях организации живого - от молекулярного и субклеточного до органного и организменного на самых различных биологических объектах. Значительные успехи достигнуты в изучении холодоустойчивости растений. Определено, что для большинства сельскохозяйственных растений низкие температуры не губительны. Связано это с тем, что при охлаждении ферментативный аппарат растений не расстраивается, не снижается устойчивость к грибным заболеваниям и не происходит заметных повреждений растений [15].

Все исследования в области криобиологии ставят своей задачей создание низкотемпературного банка геномов и половых соматических клеток растений, находящихся под угрозой исчезновения, а также уникальных форм, представляющих реальную и потенциальную ценность в качестве продуцентов биологически активных либо необходимых для нужд хозяйства веществ.

При анализе механизмов действия ультранизких температур на растения особо важное значение уделяется вопросам кооперативной неспецифической адаптации и реактивности организма, поскольку изучение происходящих при этом процессов позволяет ближе подойти к пониманию специфических действий тех или иных фракторов среды на структурно-функциональном и физиолого-биохимических уровнях клетки, от которых в конечном итоге зависит та или иная форма устойчивости растений. И здесь очень важное место имеет закалка растений, различные способы повышения устойчивости к действию экстремальных фракторов и стрессов [14]. Следовательно, на основании этого можно предположить, что растения, прошедшие интенсивную закалку, могут быть резистентными к низким температурам. Таким образом, медленное ступенчатое снижение температуры позволяет повысить устойчивость ткани до такой степени, что у них появляется способность выдерживать действие снежного слоя, а периодическая обработка слоем снега позволяет подготовить семенной материал к адаптации пониженных температур.

“Болиева Зарема Адесовна - к. с.-х. н., ст. н. с. отдела селекции и семеноводства картофеля

Горского государственного аграрного университета, г. Владикавказ (bolieva.z.50@таil.ru). 
Продолжительность вегетационного периода (дни) в зависимости от воздействия снега с агрорудами на растения картофеля (2006-200722.)

\begin{tabular}{|c|c|c|c|}
\hline Варианты опыта & $\begin{array}{c}\text { Начало всходов, чис- } \\
\text { ло, месяц }\end{array}$ & $\begin{array}{c}\text { Полные всхо- } \\
\text { ды, число, ме- } \\
\text { сяц }\end{array}$ & $\begin{array}{c}\text { Продолжительность } \\
\text { вегетационного пе- } \\
\text { риода, дни }\end{array}$ \\
\hline Контроль - без обработок & 03.04 & 06.04 & 87 \\
\hline $\begin{array}{l}\text { 4-5-кратная обработка сне- } \\
\text { гом }\end{array}$ & 30.03 & 03.04 & 80 \\
\hline $\begin{array}{l}\text { 4-5-кратная обработка сне- } \\
\text { гом+аланит }\end{array}$ & 30.03 & 04.04 & 80 \\
\hline $\begin{array}{l}\text { 4-5-кратная обработка сне- } \\
\text { гом+лескенит }\end{array}$ & 02.04 & 05.04 & 70 \\
\hline $\begin{array}{l}\text { 4-5-кратная обработка сне- } \\
\text { гом+ирлит-1 }\end{array}$ & 01.04 & 03.04 & 70 \\
\hline
\end{tabular}

Снежная технология приемлема во всех регионах, не только в России, но и за рубежом, где возделывается картофель, в условиях короткого лета здесь можно выращивать эту культуру по снежной технологии. В дополнительную стоимость этого проекта входит обработка семян картофреля снегом. В настоящее время семена становятся проблемой номер один, нужны здоровые клубни, полученные по меристемной, клоново отборной технологии. Известно, это дорогостоящий процесс, который длится от 3 до 6 лет. Переборка вручную не дает должного результата. Семена, полученные такими способами, - дорогое удовольствие.

Снежная технология, в отличие от этого, дает возможность подготавливать здоровый элитный семенной материал без дополнительных расходов.

Таким образом, проведение поисковых исследований подтвердило новизну проводимых экспериментов по использованию снега при подготовке семенного материала для адаптации в конкретных условиях произрастания.

\section{УСЛОВИЯ И МЕТОДИКА ИССЛЕДОВАНИЙ}

Наши исследования по использованию снежной технологии в комплексе со стимуляторами роста проводились в Пригородном районе РСО-А в колхозе «По заветам Ильича» в 2006-2007 гг.

Проращивание клубней картофеля сорта Владикавказский мы производили в помещении при температуре +10-12 С. Четырех-пятикратную обработку клубней с едва проклюнувшимися ростками снегом слоем в 2-4 см начали 15 января с интервалом 7-8 дней. Снег смешивали с природными агрорудами - лескенитом, аланитом и ирлитом-1. Талой водой, с растворенными в ней агрорудами обволакивали клубни, сохра- няя влагу и питая развивающиеся из глазков ростки. После третьей обработки клубней снегом цвет развивающихся росточков становится темнозеленым, а ростки более жизнеспособными. Это можно объяснить тем, что в ростках проросших клубней формируется хлорофилл, который впоследствии влияет на фотопотенциал фотосинтеза, имеющего основное значение в формировании урожая [1].

Обработанные клубни высадили в І декаде марта (температура почвы 5-6 으 и воздуха 7-8 ㄱ).

\section{РЕЗУЛЬТАТЫ ИССЛЕДОВАНИЙ}

Результаты оценки вариантов по продолжительности вегетационного периода при использовании элементов снежной технологии отображены в таблице 1.

Анализируя данные наблюдений за период 2006-2007гг., мы определили, что полные всходы обработанных клубней развивались на 3-4 дня раньше контрольного варианта. Длина вегетационного периода сократилась в разрезе вариантов по сравнению с контролем на 7-17 дней.

Следовательно, предпосадочная обработка клубней картофеля снегом в сочетании с природными цеолитсодержащими глинами сокращает вегетационный период растений картофеля на 7-17 дней, что дает возможность избежать поражения картофеля болезнями и вредителями, получить здоровый ранний урожай клубней.

Доказано, что рост и накопление биомассы являются важнейшими характеристиками продукционного процесса и отражают способность культур к реализации своих потенциальных возможностей в конкретных условиях произрастания. Вклад листьев в формирование урожая определяется активностью фотосинтетического аппарата, продолжительностью его жизненного 
Площадь листьев (тыс. м²/га) картофельного растения в зависимости от снежной обработки в комплексе с природными цеолитсодержащими глинами (2006-2007 гг.)

\begin{tabular}{|c|c|c|c|c|}
\hline \multirow[t]{2}{*}{ Вариант } & \multicolumn{4}{|c|}{ Фазы развития } \\
\hline & Бутонизация & Цветение & $\begin{array}{c}\text { Формирование } \\
\text { клубней }\end{array}$ & $\begin{array}{l}\text { Зрелые } \\
\text { клубни }\end{array}$ \\
\hline $\begin{array}{l}\text { Контроль - без обра- } \\
\text { ботки }\end{array}$ & 25,08 & 37,68 & 39,02 & 15,73 \\
\hline $\begin{array}{l}\text { 4-5-кратная обработка } \\
\text { снегом }\end{array}$ & 26,09 & 38,70 & 45,03 & 15,04 \\
\hline $\begin{array}{l}\text { 4-5-кратная обработка } \\
\text { снегом+аланит }\end{array}$ & 29,08 & 42,69 & 51,66 & 15,53 \\
\hline $\begin{array}{l}\text { 4-5-кратная обработка } \\
\text { снегом+лескенит }\end{array}$ & 32,35 & 46,02 & 53,64 & 13,73 \\
\hline $\begin{array}{l}\text { 4-5-кратная обработка } \\
\text { снегом+ирлит-1 }\end{array}$ & 42,51 & 54,14 & 55,60 & 14,56 \\
\hline
\end{tabular}

цикла, положением листа в системе целого растения.

Известно, что для картофеля определяющим является быстрое фоорирование ассими-ляционного аппарата, сопровождающееся усиленным вегетационным развитием благодаря повышенной активности гиббереллинов - ростовых гормонов, что свойственно растениям, семена которых яровизированы при резких перепадах температуры в освещенном помещении.

Результаты наших исследований показали, что у клубней, обработанных снегом перед посадкой, происходит более интенсивный рост листовой поверхности и увеличивается продолжительность сохранения максимальной площади листьев.

Из приведенных данных таблицы 2 следует, что максимальная площадь листьев 54,14-55,60 тыс. м²/га отмечена в период цветения и формирования клубней на варианте 4-5-кратной обработки снегом с ирлитом-1, а также с лескенитом (46,02-53,64 тыс. м²/га), обладающими комплексом макро- и микроэлементов, необходимых растению. К фазе созревания площадь листьев резко сократилась, достигнув 14-15 тыс. м²/га в среднем за 2006-2007 годы.

Таким образом, исследованиями установлено, что 4-5-кратная обработка клубней перед посадкой снегом в сочетании с лескенитом и ирлитом-1 способствует формированию максимальной площади листьев - 54,14-55,60 тыс. м²/га в период цветения и формирования клубней.

Проведенные нами исследования подтвердили, что снежная обработка клубней перед посадкой значительно снижает заболеваемость растений вирусными болезнями. На основе данных по полученному урожаю можно предположить, что резкие колебания температурного режима способствуют снижению инфекционного распространения болезней на посадках картофреля, в результате формируется оздоровленный посадочный материал.

В период вегетации было отмечено, что на растения картофреля сорта Владикавказский, клубни которого были обработаны снегом, проявление симптомов вирусных и грибных болезней было незначительным, т. е. пораженность была низкой - таблица 3.

Как видно по данным таблицы, пораженность растений картофеля, клубни которых были обработаны снегом, наиболее распространенными вирусными болезнями (морщинистая, крапчатая мозаиками, скручиванием и закручиванием листьев) была меньше. По данным визуальной оценки она составила от 0,2 до 0,4 \%, что ниже контроля на 0,5-0,7 \%. Показатели серологического анализа не превышали 0,1-1,2 \%. По результатам иммунноферментного анализа на скрытую инфекцию, растения картофеля были поражены в вариантах снег+ирлит-1 и снег+лескенит соответственно на 0,7 и 0,4 \%, или ниже контрольного варианта на 3,3 \% и 3,6 \%. В тех же вариантах растения картофеля по пораженности фритофторой были оценены высоким баллом 9 как по ботве, так и по клубням. В вариантах обработка снегом и снегом+аланит пораженность фитофторой ботвы и клубней соответственно была оценена также высокими баллами устойчивости 8 и 9. От стеблевой нематоды во всех вариантах клубни были свободные по сравнению с контролем - 1,1\%.

Следовательно, применение снежной технологии в производстве семенного картофеля 
Оценка поражения вирусными и грибными болезнями растений картофеля, обработанных снегом в комплексе с цеолитсодержащими глинами перед посадкой (2006-2007гг.)

\begin{tabular}{|c|c|c|c|c|c|c|}
\hline \multirow[t]{2}{*}{ Вариант } & \multirow[t]{2}{*}{$\begin{array}{c}\text { Визуальная } \\
\text { оценка, \% }\end{array}$} & \multirow[t]{2}{*}{$\begin{array}{c}\text { Серологическая } \\
\text { оценка, \% }\end{array}$} & \multirow[t]{2}{*}{$\begin{array}{l}\text { ИФА } \\
\%\end{array}$} & \multicolumn{2}{|c|}{$\begin{array}{c}\text { Поражённость } \\
\text { фитофторой, } \\
\text { балл }\end{array}$} & \multirow{2}{*}{$\begin{array}{c}\text { Пораженность } \\
\text { стеблевой нема- } \\
\text { тодой клубней, } \\
\% \\
\end{array}$} \\
\hline & & & & ботвы & клубней & \\
\hline \multicolumn{7}{|c|}{ Без обработки клубней перед посадкой } \\
\hline Контроль & 0,9 & 2,8 & 4,0 & 7 & 7 & 1,1 \\
\hline \multicolumn{7}{|c|}{ Предпосадочная обработка клубней } \\
\hline $\begin{array}{l}\text { 4-5-кратная обработ- } \\
\text { ка снегом }\end{array}$ & 0,4 & 1,2 & 1,3 & 8 & 9 & 0 \\
\hline $\begin{array}{l}\text { 4-5-кратнаяобработ- } \\
\text { ка снегом+аланит }\end{array}$ & 0,3 & 0,9 & 1,1 & 8 & 9 & 0 \\
\hline $\begin{array}{l}\text { 4-5-кратная обработ- } \\
\text { ка снегом+лескенит }\end{array}$ & 0,2 & 0,1 & 0,7 & 9 & 9 & 0 \\
\hline $\begin{array}{l}\text { 4-5-кратная обработ- } \\
\text { ка снегом+ирлит-1 }\end{array}$ & 0,2 & 0,1 & 0,4 & 9 & 9 & 0 \\
\hline
\end{tabular}

снижает пораженность растений вирусными болезнями, а низкие перепады температур способствуют выработке иммунитета растений картофреля к фитофторозу до 8-9 баллов.

Качество клубней любого сорта картофеля зависит прежде всего от влияния внешних условий, т. е. питательных веществ почвы, ее влажности и кислотности, температурного режима не только почвы, но и воздуха в разные сезоны года, от которых в свою очередь зависит работа фотосинтетического аппарата листа. Не следует забывать и о сортовых особенностях [9, 10, 11].

Как отмечает в своих исследованиях Maruman Н.Т., при снежной технологии реакция различных сортов имеет некоторые изменения в зависимости от генотипа и свойства организма на отзывчивость к холоду.

Особенно по этим показателям выделились варианты снег+лескенит и снег+ирлит-1, превы- шающие контроль по крахмалу на 1,8 и 2,8 \%, сухому веществу на 4 и 4,3\%, витамину «С» на 0,92 и 1,52 \%. Редуцирующие сахара, характеризующиеся как отрицательный показатель клубней (потемнение мякоти) в 3-, 4-, 5-м вариантах под действием перепадов температур снизились с 1,01 до 0,62 \%. Снижение редуцирующих сахаров в клубнях - это положительный показатель при промышленной переработке клубней картофеля.

Семена любой культуры надо рассматривать как биологическую систему, состоящую из двух основных частей - зародыша и питательного вещества. Поэтому в ходе обработки семян технологические режимы не должны нарушать состояние зародыша и запасного питательного вещества.

Ввиду этого следует как можно точнее определить размеры наклюнувшихся ростков (2-3

Таблица 4

Биохимический состав клубней картофеля, обработанных снегом в комплексе с природными цеолитсодержащими глинами

(2006-2007гг.)

\begin{tabular}{|c|c|c|c|c|}
\hline \multirow[t]{2}{*}{ Вариант } & \multicolumn{4}{|c|}{ Содержание в клубнях } \\
\hline & $\begin{array}{c}\text { Крахмала, } \\
\text { \% }\end{array}$ & $\begin{array}{l}\text { Сухое ве- } \\
\text { щество, \% }\end{array}$ & $\begin{array}{l}\text { Витамин } \\
« \text { С», мг \% }\end{array}$ & $\begin{array}{l}\text { Редуцирующие } \\
\text { сахара, \% }\end{array}$ \\
\hline $\begin{array}{l}\text { Контроль - без обра- } \\
\text { ботки }\end{array}$ & 13,6 & 17,9 & 3,28 & 1,01 \\
\hline $\begin{array}{l}\text { 4-5-кратная обработка } \\
\text { снегом }\end{array}$ & 14,4 & 18,7 & 3,68 & 0,89 \\
\hline $\begin{array}{l}\text { 4-5-кратная обработка } \\
\text { снегом+аналит }\end{array}$ & 15,3 & 21,4 & 3,88 & 0,66 \\
\hline $\begin{array}{l}\text { 4-5-кратная обработка } \\
\text { снегом+лескенит }\end{array}$ & 16,4 & 22,2 & 4,8 & 0,62 \\
\hline $\begin{array}{l}\text { 4-5-кратная обработка } \\
\text { снегом+ирлит-1 }\end{array}$ & 15,4 & 21,9 & 4,2 & 0,64 \\
\hline
\end{tabular}




\section{Структура урожая картофеля и его качество под воздействием снежной}

Таблица 5 технологии в сочетании с цеолитсодежащими глинами (2006-2007гг)

\begin{tabular}{|l|c|c|c|c|}
\hline \multicolumn{1}{|c|}{ Вариант } & $\begin{array}{c}\text { Грамм на } \\
\text { куст. }\end{array}$ & $\begin{array}{c}\text { Средняя масса 1- } \\
\text { го товарного } \\
\text { клубня, г }\end{array}$ & $\begin{array}{c}\text { \% товарных } \\
\text { клубней }\end{array}$ & $\begin{array}{c}\text { Урожай, } \\
\text { т/га }\end{array}$ \\
\hline Контроль - без обработок & 300,5 & 65,5 & 60,0 & 14,2 \\
\hline $\begin{array}{l}\text { 4-5-кратная обработка сне- } \\
\text { гом }\end{array}$ & 380,0 & 68,4 & 62,2 & 19,6 \\
\hline $\begin{array}{l}\text { 4-5-кратная обработка } \\
\text { снегом+аланит }\end{array}$ & 495,0 & 75,0 & 72,5 & 19,6 \\
\hline $\begin{array}{l}\text { 4-5-кратная обработка } \\
\text { снегом+лескенит }\end{array}$ & 550,5 & 80,5 & 88,0 & 25,5 \\
\hline 4-5-кратная снегом+ирлит-1 & 520,0 & 80,7 & 90,0 & 24,4 \\
\hline \multicolumn{1}{|l}{ НСР } \\
\hline
\end{tabular}

мм) из глазков клубня, чтобы не нарушить стабильный рост перепадом температур, т. к. формирование урожая во многом зависит от состояния ростков $[2,5]$.

Результаты наших исследований свидетельствуют, что применяемая технологическая схема способствует значительному увеличению урожая картофреля.

Из приведенных данных таблицы 5 видно, что наиболее оптимальными вариантами являются обработка клубней перед посадкой снегом в смеси с лескенитом и ирлитом, где урожайность превышает контроль на 10,2 и 11,3 т/га. Превышение продуктивности на этих вариантах наблюдалось за весь период исследований (2006-2007 гг.).

Одним из основных достоинств снежной тех- нологии является формирование высокой товарности клубней. Так, в наших исследованиях процент товарных клубней отмечен по вариантам снег+лескенит и снег+ирлит-1 от 88,0 до $90 \%$, а средняя масса одного товарного клубня составила от 80,5 до 80,7 г, что является оптимальным при заготовке семенного материала. Накопление средней массы клубней с одного куста выше контрольного варианта на 220 и 250 г происходило также на этих вариантах.

Необходимо отметить, что полученный семенной материал с помощью снежной технологии не требует дополнительной обработки на следующее поколение, поскольку адаптирован к пониженным температурам, имеет оптимальные фрракции, свободен от вирусных и грибных заболеваний, способен усвоить достаточное количе-

Таблица 6

Экономическая эффективность возделывания картофеля при использовании элементов снежной технологии

\begin{tabular}{|c|c|c|c|c|c|c|c|c|}
\hline Варианты опыта & 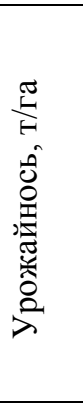 & 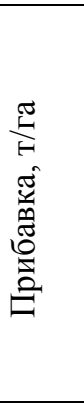 & 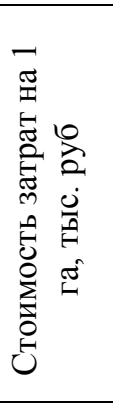 & 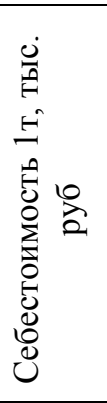 & 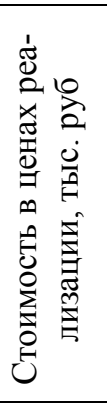 & 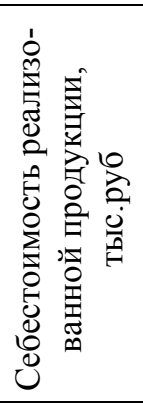 & 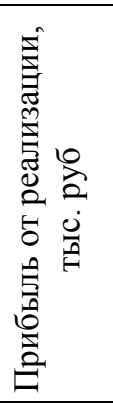 & 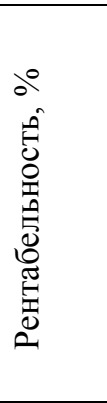 \\
\hline Контроль - без обработок & 14,2 & - & 65,0 & 4577 & 142,0 & 65,0 & 77,0 & 118,0 \\
\hline $\begin{array}{l}\text { 4-5-кратная обработка } \\
\text { снегом }\end{array}$ & 19,6 & 5,4 & 66,3 & 3382 & 196,0 & 66,3 & 129,7 & 195,6 \\
\hline $\begin{array}{l}\text { 4-5-кратная обработка } \\
\text { снегом+аланит }\end{array}$ & 23,2 & 9,0 & 68,2 & 2939 & 232,0 & 68,2 & 163,8 & 240,1 \\
\hline $\begin{array}{l}\text { 4-5-кратная обработка } \\
\text { снегом+лескенит }\end{array}$ & 25,5 & 11,3 & 68,4 & 2682 & 255,0 & 68,4 & 186,6 & 272,8 \\
\hline $\begin{array}{l}\text { 4-5-кратная обработка } \\
\text { снегом+ирлит-1 }\end{array}$ & 24,4 & 10,2 & 68,0 & 2787 & 244,0 & 68,0 & 176,0 & 258,2 \\
\hline
\end{tabular}


ство питательных веществ за период вегетации.

Как показывают наши расчеты, 4-5-кратная обработка клубней снегом перед посадкой повысила стоимость затрат на 1 гектар всего на 1,3 тыс. рублей, тогда как прибыль составила 42,7 тыс. рублей, а рентабельность 77,1 \%. На вариантах с использованием снега и агроруд эти показатели повысились соответственно с аланитом - до 163,8 тыс. рублей, что составило 240,1 \%; с лескенитом - до 186 тыс. рублей, а процент повысился до 272,8; с ирлитом-1 - до 176,0 тыс. рублей, а рентабельность - 258,8 \%.

\section{Выводы}

1. Предпосадочная обработка клубней картофреля снегом в комплексе с природными агрорудами сокращает вегетационный период на 7-17 дней, что дает возможность избежать поражение картофеля болезнями и вредителями, получить более ранний здоровый урожай клубней.

2. Доказано, что у клубней, обработанных снегом перед посадкой, происходит более интенсивный рост площади листовой поверхности. На вариантах снег+лескенит и снег+ирлит-1 площадь ассимиляционной поверхности составила 54,14-55,60 тыс. м²/га, что выше контроля на 16,5-16,6 тыс. м²/га;
3. Предпосадочная обработка клубней снегом в смеси природными цеолитсодержащими глинами резко снижает заболеваемость вирусами визуально с 0,9 до 0,2 \%, по иммуноферментой оценке с 2,8 до 0,1-1,2 \%, повышает иммунитет растений картофеля против фитофрторы до 8-9 баллов, поврежденность растений картофеля стеблевой нематодой снизилась с 1,1 до $0 \%$.

4. Обработка клубней картофеля перед посадкой снегом в комплексе с аланитом, лескенитом и ирлитом-1 способствует увеличению содержания крахмала в 3-, 4-, 5-м вариантах на $1,8-2,8 \%$, сухого вещества на 4,0-4,3 \%, чем на контроле. По содержанию витамина «С» выделились 4-й и 5-й варианты - 4,2-4,8 мг \%. Было установлено снижение содержания редуцирующих сахаров с 1,01 до 0,62 \%;

5. Значительные прибавки урожая при предпосадочной обработке клубней снегом наблюдались на вариантах снег+лескенит и снег+ирлит-1, или на 10,2-11,3 т/га выше контрольного варианта.

Такое превышение урожая следует объяснить адаптацией к низким температурам, здоровым состоянием растений картофеля под воздействием уникальных свойств цеолитсодержащих глин.

\section{ЛИТЕРАТУРА}

1. Андрианова Ю.Л., Тарчевский Н.А. Хлорофрилл и продуктивность растений. -М.: Наука. 2000. 135с.

2. Бекузарова С.А., Болиева З.А., Басиев С.С., Доева Л.Ю. Способ подготовки клубней картофреля к посадке. Патент на изобретение RUS 2549293 21.05.2013.

3. Болиева 3.А. Влияние природных агроруд и стимуляторов роста на продуктивность и качество картофеля в лесостепной и горной зонах РСО-Алания: авторефр. дис. ... канд. с.-х. наук. Горский государственный аграрный университет. - Владикавказ, 2010. 147с.

4. Болиева З.А., Доева Л.Ю., Солдатова Т.Б., Драева Л.Б., Бацазова Т.М. Применение цеолитовых глин для повышения продуктивности и товарности клубней картофеля // Научная жизнь. 2012. № 4. С. 15-21.

5. Болиева З.А., Доева Л.Ю., Лихненко С.В. Оченка качества клубней отечественных и зарубежных сортов картофреля в условиях предгорной зоны РСО-Алания// Научная жизнь. 2015. №1. С. 70-73.

6. Болиева 3.А., Доева Л.Ю., Тедеева А.А., Драева Л.Б. Влияние цеолитсодержащих глин на продуктивность и качество картофреля // Известия Горского государственного аграрного университета. 2013. T. 50. № 1. С. 80-84.

7. Доева Л.Ю. Влияние биомелиорантов и удобрений на плодородие выщелоченного чернозема и продуктивность картофреля в лесостепной зоне РСО-Алания. Диссертация на соискание ученой степени кандидата сельскохозяй- ственных наук / Горский государственный аграрный университет. - Владикавказ, 2006.

8. Доева Л.Ю., Мамиев Д.М., Болиева З.А. Плодородие почвы и продуктивность картофреля при применении биомелиорантов и удобрений в РСО-Алания // Плодородие. 2010. № 3. C.31-32.

9. Зангиева Ф.Т., Лихненко С.В. Оценка урожайности и устойчивости к вирусным и грибным болезням клубней гибридных популяций картофреля // Вестник Владикавказского научного центра. 2015. T.15. №2. С.41-46.

10. Лихненко С.В., Доева Л.Ю., Зангиева Ф.Т. Новые сорта картофеля для Северо-Кавказского региона // Вестник Владикавказского научного центра. 2016. T.16. №4. С.62-69.

11. Сердеров В.К., Атамов Б.К., Сердерова Д.В. Новые перспективные сорта для развития отрасли картофрелеводства в Дагестане // Горное сельское хозяйство. 2015. №5. C.77-80.

12. Пушкарёв. Н.С., Белоус А.М. Введение в криобиологию. - Киев: «Наукова думка», 1995.

13. Туманов И.И. Физиологические основы зимостойкости культурных растений. - М.-Л.: Изд-во АН СССР. 1970. 152с. 14. Удовенко Г.В. Механизмы адаптации растений к стрессам // Физиология и биохимия культурных растений. 1979. № 2. C.99-107.

15. Холодовой стресс и биологические системы (под редакцией Цуциевой А.А.). - Киев: «Наукова думка», 1991. 


\title{
USING THE ELEMENTS OF SNOW TECHNOLOGY IN \\ COMBINATION WITH NATURAL-MI AGROORES AT \\ PREPLANT TREATMENT OF POTATO TUBERS
}

\author{
Z.A.Bolieva*
}

PhD, Gorsky State Agrarian University, Vladikavkaz

BolievaZaremaAdesovna ((8672) 63-02-38; bolieva.z.50@mail.ru).

Abstract. The present article dwells upon the results of the effect of low temperatures study in combination with natural agricultural ores (leskenit, alanit and irlit-1) for the duration of the vegetative season, the formation of leaf area, the biochemical composition of the pulp, tuber's stability to illnesses and potato yield. The snow technology elements use efficiency has been proved in combination with natural agricultural ores.

Keywords: potatoes, snow technology, alanit, leskenit, irlit-1.

\section{REFERENCES}

1. Andrianova Y.L. Tarchevsky N.A. Chlorophyll and plant productivity. M.: Science. 2000. 135p. 2. Bekuzarova S.A., Bolieva ZA, Basiev S.S., Doeva L.Y. A method of preparing potatoes for planting.A patent for an invention RUS 05/21/2013 2549293.

3. Bolieva Z.A. Influence of natural agroores and growth stimulants on productivity and quality of a potato in forest-steppe and mountain areas of North Ossetia-Alania. Thesis for a candidate degree for Agricultural Sciences / Gorsky State Agrarian University. Vladikavkaz. 2010.

4. Bolieva Z.A., Doeva L.Y., Soldatova T.B., Draeva L.B., Batsazova T.M. The use of zeolite clays to enhance productivity and marketability of potato tubers. Scientific life. № 4. 2012. pp 15-21.

5. Bolieva Z.A., Doeva L.Y., Lihnenko S. V. Evaluation of the quality of tubers of domestic and foreign varieties of potato in the conditions of a foothill zone of North Ossetia-Alania. Scientific life. 2015. №1. P. 70-73.

6. Bolieva ZA, Doeva L.Y., Tedeyeva A.A., Draeva L.B. Influence tseolitsoder-containing clayproductivity and quality of a potato. News of Gorsky State Agrarian University. 2013. T. 50. № 1. P. 80 - 84.

7. Doeva L.Y. Influence biomeliorants and fertilizers on fertility black soil and potato productivity in steppe zone of North Ossetia-Alania. Thesis for a candidate degree for Agricultural Sciences / Gorsky State Agrarian University.Vladikavkaz. 2006.

8. Doeva L.Y., Mamiev D.M., Bolieva Z.A. Soil fertility and potato products in the application of fertilizers and biomeliorants in North Ossetia-Alania. Fertility. 2010. №3 P.31-32.

9. Pushkarev N.S., Belous A.M. Introduction to cryobiology. Kiev. "NaukovaDumka". 1995.

10. Mist II Physiological basis hardiness of crops. - M.-L.: Publishing House of the USSR Academy of Sciences. 1970. 152p.

11. Udovenko G.V. The mechanisms of plant adaptation to stress // Physiology and biochemistry of cultivated plants. 1979. № 2. P.99-107.

12. Cold stress and biological systems (edited Tsutsieva AA) Kiev, "NaukovaDumka". 1991.

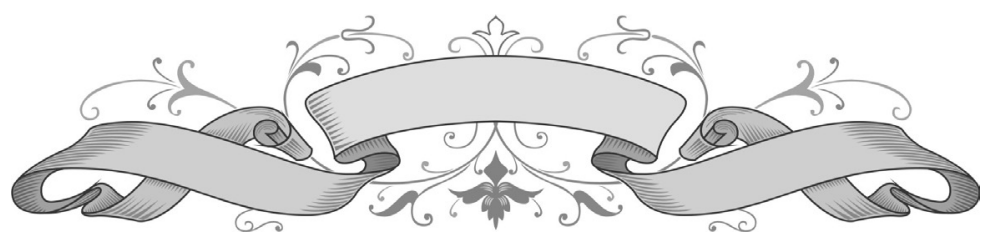

